\title{
Introduction to the Journal Issue
}

\section{Attending to Outcomes, Relationships, and Processes to Advance Democratic Practices in Service-Learning and Community Engagement}

\author{
Clayton A. Hurd
}

International Journal of Research on Service-Learning and Community Engagement

Glenn A. Bowen

International Journal of Research on Service-Learning and Community Engagement

\section{Recommended Citation:}




\title{
Attending to Outcomes, Relationships, and Processes to Advance Democratic Practices in Service-Learning and Community Engagement
}

\author{
Clayton A. Hurd \\ Glenn A. Bowen \\ International Journal of Research on Service-Learning and Community Engagement
}

\begin{abstract}
Service-learning and community engagement (SLCE) scholar-practitioners in higher education have shifted their focus to deeper engagement and more democratic practices. They have been paying closer attention to the need for engagement practices to be based on mutuality and a genuine commitment to the co-creation of knowledge. Increased attention to questions of relationships, power, and processes in SLCE has become particularly salient in investigations of student learning in community-based experiences. Articles in Volume 8, Issue 1 of the International Journal of Research on Service-Learning and Community Engagement (IJRSLCE) draw attention to research that reflects three lines of inquiry that, in essence, emphasize reciprocity in partnerships between higher education institutions and the wider community. The implication is that SLCE in higher education continually requires critical reflection on the extent to which partnerships and processes combine effectively to enhance student learning; build community capacity; and transform systems, individuals, organizations, communities, and higher education itself.
\end{abstract}

Keywords: campus-community partnerships, co-creation of knowledge, democratic engagement, reciprocity, transformational engagement

Since the early 2000s, higher education institutions throughout the United States have more deliberately embraced community engagement as a defining feature of their mission and work. It was in 2006 that the Carnegie Foundation for the Advancement of Teaching articulated the purposes and processes of community engagement with the launch of its Elective Classification for Community Engagement. The articulation document (called the Classification Documentation Framework) provides what is considered the most influential expression of the processes and the purposes that characterize "the engaged campus" (Saltmarsh et al., 2015, p. 122).

In defining community engagement, the Carnegie Foundation has made it clear that "partnerships and reciprocity" are key elements:

Community engagement describes collaboration between institutions of higher education and their larger communities (local, regional/state, national, global) for the mutually beneficial exchange of knowledge and resources in a context of partnership and reciprocity. (Public Purpose Institute, n.d., emphasis added)

The partnerships themselves "require ... intentional practices specifically directed to reciprocity and mutuality" (Saltmarsh \& Johnson, 2020, p. 112). Further, as Saltmarsh and Johnson have emphasized, "the values, components, and principles of partnerships between those in the university and those outside the university are grounded in the qualities of reciprocity; mutual respect; shared authority; and cocreation of knowledge, learning, goals, and outcomes" (p. 112). Such partnerships are essential to effective, ethical practices in the established field of service-learning and community engagement (SLCE).

In recent years, both across the United States and in a growing number of countries, there has been a clear shift in how practitioner-scholars think about, plan for, and problematize community engagement in higher education. They have been paying closer attention to the need for engagement practices to be based on mutuality and a genuine commitment to the co-creation of knowledge. This has generated 
deeper, critical interrogation into the ways that SLCE programs are structured, organized, delivered, and evaluated. Assessments include the consideration of whether partnerships are characterized primarily by transactional exchanges - where partners work toward separate goals - and technocratic forms of engagement - which tend to prioritize academic over community-based knowledge - or whether they embody more democratic, transformational modes of engagement. Democratic community engagement reflects an equity-oriented, less hierarchical approach; it thrives on equitable contributions from all stakeholders and facilitates a multidirectional flow of knowledge and resources. Genuine democratic engagement is inclusive of community partners not merely for their "voices" or "input" but especially for their valued expertise and shared authority as both co-creators and co-educators (Kennedy et al., this issue; Saltmarsh et al., 2009; see also Moore, 2014, p. ix).

The current shift in scholarly inquiry is evident in a high level of interest among SLCE scholarpractitioners in understanding and practicing "deep engagement" (Saltmarsh et al., 2015, p. 123). This shift indicates an acknowledgment that legitimate knowledge exists within communities and that collaborators outside the academy also bring resources and strengths to the partnership. Creating reciprocal partnerships between academic institutions and their larger communities requires a deliberate, ongoing process of relationship development that positions all stakeholders as co-learners, co-educators, and co-generators of knowledge. Only partnerships undertaken in this way can move beyond transactional exchanges toward transformational possibilities for all.

The emphasis on democratic practices in SLCE has encouraged scholars to focus investigative attention not solely on the outcomes and impacts of engagement activities but also on the processes, values, and relationships that yield (or fail to yield) conditions of mutual trust, shared authority, and cocreation. Increased attention to questions of relationships, power, and processes in SLCE has become particularly salient in investigations of student learning in community-based experiences. More and more, scholars are examining not only what students learn, and the quality of that learning, but also how students learn. SLCE practitioners evidently see the importance of providing engagement environments that allow students to learn with and from one another, and from community stakeholders, in ways that enhance the students' academic success, build their professional skills, and foster cross-cultural competency.

Experienced scholar-practitioners understand that the degree of mutual respect, shared authority, and co-creation of knowledge achieved in campus-community partnerships can significantly influence the nature and quality of what students learn through community engagement experiences. For example, in cases where community partners and local residents are accorded status and legitimacy as co-educators and co-creators of knowledge - rather than simply being valued for their "voices" or for their roles as "clients" in community-based projects — students stand to derive immense benefit. Students could gain direct, invaluable access to multiple ways of knowing, being, and acting and could receive mentorship from persons who can offer unique situated knowledge and social analyses to complement students' academic, civic, sociocultural, and professional learning. Conversely, when such conditions fail to exist, SLCE experiences could perpetuate ignorance and uninformed perceptions of diversity that "reinforce hostile and exclusionary thinking and practices, as well as deeply rooted intolerance and inequality that, in turn, are reproduced beyond students' notice" (VanLeeuwen et al., this issue).

The authors contributing to this issue of IRSLCE, by and large, have addressed democratic approaches to community engagement directly or indirectly through a diverse set of studies undertaken in a variety of geographic and sociocultural contexts. Demonstrating one of the lines of inquiry, authors explore what it means to move SLCE partnerships beyond "thin" reciprocity-understood an "asymmetrical engagement" (Doughty, this issue), in which relationships tend to be unequal or unsustainable, power issues are ignored, and outcomes typically favor only students - toward "thick" reciprocity. The latter reflects deep engagement, which involves "thick" understandings of, and approaches to, the processes, partnerships, and outcomes of SLCE (Saltmarsh et al., 2015, p. 123).

In his article, Jeremy R. Dougthy addresses these issues directly based on his assessment of an international service-learning (ISL) immersion program in South Africa. Meanwhile, Lori Kniffin and colleagues, as well as Sandra Sgoutas-Emch and Kevin Guerrieri, offer assessments of diagnostic tools 
that may be utilized to support institutions, partnership programs, and individual practitioners in facilitating democratic engagement practices.

A second line of inquiry in this issue attends to questions about the quality of student learning in a range of community-engaged learning experiences. Some articles provide new evidence of the ways in which well-structured SLCE experiences generate positive outcomes for students in areas of academic content learning (Alexander et al.; Kabakova et al.), professional skill building and identity development (VanLeeuwen et al.; William \& Lee), and cross-cultural competency (Doughty; Livstrom et al.; Maakrun \& Kearney). Two articles look specifically at student learning and identity development in communityengaged work experiences (Livstrom et al.; Schulzetenberg et al.). Both articles demonstrate how noncurricular, community-based education/work experiences may provide as many benefits - academic, skill-building, civic leadership, and positive identity development - as more traditional service-learning does, particularly for undergraduates and youth of marginalized identities.

A third stream of inquiry in this issue emphasizes SLCE practitioner participation in deeper, "placerich" analyses of the community spaces in which partnerships operate. Thus, practitioners may appreciate the ways in which sociocultural factors have, over time, conditioned local patterns of privilege, stigma, and inequities in access to resources and services in ways that have generated social crises for individuals and families within community contexts (Doughty; Livstrom et al.). Authors argue that SLCE scholarpractitioners must intentionally integrate more content about these complex realities into their curriculum and pedagogy in order to support students' development of effective techniques and strategies to work respectfully and sensitively with culturally, racially, and linguistically diverse populations in specific national and community contexts.

Finally, two articles look more closely at the ways in which colonial legacies have impacted SLCE development and practice (Doughty; Kennedy et al.). They call attention to the need to create space in cross-cultural engagement activities for honest and open communication about inequitable distributions of power and resources, and to be willing, in some cases, to rebalance power relations within partnerships. Centering the perspectives and agency of those in the community whose voices historically have been dismissed, marginalized, or left unheard is seen as a means of cultivating power dynamics that are just, fair, and inclusive (Kennedy et al.; Livstrom et al.). Attending to questions of power, authority, and cocreation - along with a corresponding willingness to decenter priorities related to academic knowledge production - can help to provide conditions for the possibility of a "generativity-oriented reciprocity" (Kniffin et al., this issue). Such conditions would prevail in campus-community partnership spaces where stakeholders can work together to "produce systemic change, create new value, and/or undergo transformation in their way of being" (Dostilio et al., 2012, p. 21, as cited in Kniffin et al.).

\section{Advances in Theory and Methodology}

The Advances in Theory and Methodology section of this IJRSLCE issue features a single article, "Relational Learning With Indigenous Communities: Elders' and Students' Perspectives on Reconciling Indigenous Service-Learning." The authors are Andrea Kennedy, Katharine McGowan, Gabrielle Lindstrom, Christian Cook, Yasmin Dean, James Stauch, Cheryl Barnabe, and Stephen Price with Elder Roy Bear Chief, Grandmother Doreen Spence, and Kupuna Francine Dudoit Tagupa. Their exploratory case study critically interrogates the extent to which service-learning, as currently practiced, is appropriately "centered with" Indigenous community ways of being, knowing, and doing. By analyzing thematic interconnections from interviews with both students and Elders, the authors make a case for renaming service-learning as relational learning, giving a special nuance to its meaning in the context of Indigenous communities. The authors explain relational learning with Indigenous communities as "maintaining good relations through humility, respect, honesty, and reciprocity while responding to the interconnected priorities of the land, traditional ways, Elders, and common language."

Challenging Western epistemological dominance in service-learning is an overdue "radical reform" aimed at addressing "unequal relations of knowledge production [that] result in severely uneven distribution of resources" (Andreotti et al., 2015, as cited in Kennedy et al., this issue). Kennedy et al. 
argue that Indigenous voices should be heard in the production of knowledge. Establishing and sustaining relationships of true coproduction of knowledge and shared authority, the authors suggest, necessitates that Indigenous knowledge holders be represented in sanctioned roles within the university to formally guide interactions with Indigenous communities. The authors advocate decolonized practices in SLCE, in which reciprocity is reframed from being primarily about cooperation and agreement with the university to being placed within a more reconciliation-based framework. In doing so, practitioners would be acknowledging that engaging tensions and negotiating power relations constitute a core dimension of partners' commitment to working together.

\section{Student Outcomes (Primary, Secondary, and Higher Education)}

In the largest section of this issue, the articles explore ways in which thoughtfully designed community engagement experiences can substantially advance student learning and development in such domains as academic enhancement, identity development, cross-cultural competency, and professional skill building. All but two of the nine articles focus on undergraduate student experiences; one article explores experiences of graduate students and one addresses the learning experiences of youth of marginalized identities.

Charlene A. VanLeeuwen, Linyuan Guo-Brennan, and Lori E. Weeks discuss findings of a hermeneutic study that analyzed university students' community-based learning (CBL) experiences in Kenyan communities and describe how those experiences were influenced by the historical and sociocultural context of Kenya. Three of the key diversity issues identified in their study were (a) understanding the impact of HIV/AIDS, (b) realizing the important role that Indigenous languages play in community services and engagement, and (c) increasing awareness of social and economic disparities in Kenyan society. The findings inform the authors' call for the reconceptualization of CBL theory and praxis in health services to better engage with the racial, cultural, and socioeconomic dimensions of place, instead of relying on the problematic importation of Western pedagogies and practices into African contexts.

An article by Patricia Hrusa Williams and Carol K. Lee is based on their longitudinal, mixed methods study, which examined how participation in science-focused service-learning influenced the professional identity development of preservice elementary teachers (PSETs). As the authors state, one of the most promising insights from their study surrounds PSETs' expanded ideas about service-learning. At the start of the study, $80 \%$ of PSETs did not understand what service-learning was. By the end of their servicelearning experience, PSETs came to appreciate a teacher's role and identity as collaborators with parents and the community.

An exemplary collaboration is seen in the research and authorship of "Community Service-Learning Improves Learning Outcomes, Content Knowledge, and Perceived Value of Health Services Education." A team of university and community partners-Eileen S. Alexander, Frederick R. Browne, Angela E. Eberhart, Sean L. Rhiney, Judy Janzen, Kristin Dale, and Peggy Vazquez - report on their multiyear, cross-sectional study. They tested the hypothesis that community service-learning (CSL) coupled with team-based learning (TBL) and health services practice - compared with traditional classroom lecturesis an effective intervention to improve student learning outcomes. Their study found that CSL coupled with TBL significantly improved outcomes in a number of areas, including content knowledge, engagement, and perception of skill acquisition. Although the results are perhaps unsurprising (given what is known about the impacts of well-designed service-learning courses), the longitudinal and comparative nature of the study, along with its focus on the integration of CSL and TBL, make it a notable contribution to community-engaged scholarship.

Ka Hing Lau and Robin S. Snell evaluated the test-retest reliability and validity of their ServiceLearning Outcomes Measurement Scale (S-LOMS). The scale is designed to collect self-report data about student development in 11 domains under four broader categories: knowledge application, personal and professional skills, civic orientation and engagement, and self-awareness. A sample of university students responded to the items on the scale twice within a short period. The results indicated that $S$-LOMS is 
stable over time and that it has robust validity. The 56-item $S$-LOMS was created specifically for use in Hong Kong; it is said to be tailored to that country's institutional values. Lau and Snell noted the need for a standardized and reliable instrument to measure the effectiveness of service-learning pedagogy in fostering the desired student development outcomes, especially those related to socially responsible citizenship.

Two articles in this section explore student outcomes and perceptions in subject areas in which SLCE inquiry is still emerging. Polina Kabakova, Oliver St-Cyr, and Colin D. Furness's Canadian study adds to the small body of SLCE research in the field of user experience design (UXD). The researchers evaluated short-term outcomes of community-engaged learning (CEL) within UXD. The findings offer preliminary support for CEL initiatives in UXD education and show that CEL benefits both students and community partners. Short-term student learning outcomes include the development of interpersonal skills, empathy, and UXD-specific skills. Community partners benefited from the support of UXD students by obtaining "valuable deliverables" and "research insights" that led to the allocation of funds for the development of products and services within their organizations.

Joan Clifford, Dane Emmerling, Evan Widney, Nina Hamilton, and David Malone present an interesting study of U.S. undergraduate student perceptions of two predominant, and often perceived as competing, approaches to community engagement: service-learning and social entrepreneurship education. Their study was aimed at understanding more deeply the perceptions of service-learning and social entrepreneurship education as shared by undergraduates. The researchers examined ways in which the gender of students and their prior experiences in community engagement might shape those perceptions. Students saw the community engagement approaches as having distinctive characteristics, with service-learning being less innovative than social entrepreneurship education. The authors see the need to challenge reductive, bifurcated stereotypes about both approaches. They emphasize that highquality service-learning and social entrepreneurship practice must intentionally address ways that both may reinforce stereotyping, privilege, and power differentials.

Across the higher education landscape, there has been an explosive growth of social entrepreneurship adopted as a community engagement approach. Additionally, there is evidence of the sometimes uncomfortable articulation of social entrepreneurship with long-standing scholarship and practice within the field of SLCE (McBride \& Mlyn, 2020). Given those factors, it is important to foster innovation in their implementation while promoting understanding of the power of both approaches.

Janet Colvin investigated students' perceptions of their experiences in an intercultural communication course with a service-learning component, which required students to complete 20 hours of service in one of several local refugee centers. In her article, Colvin reports on the thematic findings of her study that involved 69 students over the course of two semesters. She noted that students generally developed increased empathy for, and interest in learning about, the refugee population in their own community.

Two particularly noteworthy contributions to the Student Outcomes section draw attention to the positive impact of non-curricular, community-engaged work experiences on the development and success of underrepresented undergraduates and youth. The first-by Anthony J. Schulzetenberg, Yu-Chi Wang, Ashley Hufnagle, Krista M. Soria, Geoffrey Maruyama, and Jason Johnson-analyzes underrepresented college students' participation in a community-engaged employment program to determine desirable outcomes. The study found that students who participated in the program had significantly higher secondyear retention rates, graduate rates, grade point averages, and number of credits completed, compared to similar students not employed in the program. As the authors point out, the findings show that community-engaged employment can provide positive academic outcomes similar to volunteer community engagement experiences while also addressing financial barriers in the path of many underrepresented students.

The other contribution that looks at a work-based program is a case study by Illana C. Livstrom, Gillian H. Roehrig, and Amy R. Smith. The program, an urban agriculture internship, brings together youth interns and mentors (undergraduates and community elders) in intergenerational garden groups. The authors point to important elements of programs to support youth, including diverse relationships and strong connections with the community. Further, the study shows the value of intergenerational mentoring 
and work, diversity in learning communities, and work-based (internship) learning. The studies discussed by both Livstrom et al. and Schulzetenberg et al. make a strong case for expanding work-based learning opportunities for marginalized and underrepresented youth in both school and out-of-school settings.

\section{Faculty Roles and Institutional Issues}

In the only published contribution to this section, James M. Lewing shares his study on the professional development preferences of experienced community-engaged faculty members at a set of public, fouryear, higher education institutions in the United States that have a record of sustained institutionalization of community engagement. Lewing found that when asked about their desire for more advanced professional development, experienced faculty members identified support for continued community partnership building as their first choice, followed by support for facilitating curricular community engagement and conducting community-based research. Given the prevalent focus on entry-level or introductory development programs to support community-engaged faculty, the study's aim - to gain a deeper understanding of what experienced faculty might value as next-level developmental training - is particularly pertinent.

The fact that community partnership building topped the list speaks to faculty members' real interest in engaging with the complexity of developing and sustaining high-quality partnerships. It also suggests an acknowledgement that reflection on prior experience, along with deeper explorations of meanings and models of partnerships, may help faculty move from transactional to transformational relationships that reflect more democratic modes of engagement.

\section{Community Partnerships and Impacts}

The articles in this section (both with informative illustrations) offer analyses of different diagnostic learning tools intended to inform inquiry and improve the quality of campus-community partnerships. In their article, Sgoutas-Emch and Guerrieri discuss their research on the efficacy of a model of social change - a lens through which to assess the quality of community partnerships in relation to course-based community engagement projects. Having tested the model with a set of the faculty and community partner representatives, the authors cite its efficacy as an instrument for stakeholders to use in identifying areas of satisfaction and success, as well as to report barriers and weaknesses in the capacity of the partnerships. Significantly, the diagnostic model allows community partners to air frustrations and identify desires to deal with challenges. In Sgoutas-Emch and Guerrieri's study, community partners identified, among other things, "the need for co-creation at earlier stages in the [partnership/project implementation] process in order to reduce frustration."

Whereas the diagnostic tool that Sgoutas-Emch and Guerrieri described was developed by one institution to assess the quality of networked relationships in a particular place-based collaboration, the assessment tool described in the second article was developed for use across multiple partnership contexts. The authors of that article are Kniffin and colleagues-Jasmina Camo-Biogradlija, Mary F. Price, Emily Kohl, Jamie Williams, Alessandra Del Conte Dickovick, Jamie Goodwin, Kristi V. Johnson, Patti H. Clayton, and Robert G. Bringle. The Transformational Relationship Evaluation Scale (TRES) was developed as a tool for assessing the quality of community-campus relationships. The utility of TRES is considered in modes of inquiry (i.e., reflection, assessment, and research) and purposes of inquiry (e.g., relationship development, program capacity building/refinement, and knowledge generation).

In addition, the authors share the lessons learned through TRES and implications for further inquiry and practice. The authors' willingness to reflect on both the successes and limitations of the use of the tool in various contexts - and to provide information on cases where the tool has required significant modifications - make for an informative and insightful read. Acknowledging the inherently iterative approach to the development of the tool, the authors reveal that each use has sharpened their understanding of TRES itself and of what is needed to help it reach its full potential as a vehicle for 
reflection, assessment, and research. Essentially, the TRES model, as well as their treatment of it, embodies the spirit of SLCE as reflective, collaborative, and evolving inquiry and practice.

\section{International Service-Learning and Community Engagement Research}

This section is composed of two articles. Julie Maakrun and Sean Kearney share the findings of their research on an immersion program in Kenya, which was designed to deepen students' cultural competence and help to prepare them as culturally responsive teachers in a demographically diverse Australian context. Their study looked specifically at students' pretravel motivations and found that students' most prevalent desires were to better understand themselves, make a difference, and connect with one another and with members of the host community, as well as to step outside their comfort zone. Students' perspectives seemed to align with the program's goals to provide an immersion experience that fosters personal transformation and professional learning, and well as to respond appropriately to cultural diversity by developing global-mindedness and awareness of critical social issues.

Whereas Maakrun and Kearney defer consideration of the motivations or expectations of community partners as co-creators in the ISL partnership, Doughty's study in South Africa gives full attention to the perceptions of the community partner. His study focuses on the partnership component of an ISL immersion program with a primary school in a predominantly Black African, Xhosa-speaking township in the Western Cape province of South Africa. The analysis of findings provides an insightful discussion of the distinctions between "technocratic" and "democratic" engagement (see Saltmarsh et al., 2009), as well as between "thin" and "thick" reciprocity (Saltmarsh et al., 2015, p. 123; see also Jameson et al., 2011). The author also articulates a number of ways in which the problematics of the partnership could be remedied and relationships strengthened to create more effective outcomes.

\section{Book Reviews}

Two book reviews are presented in this issue. In the first, Heidi Whitford critiques Democracy, Civic Engagement, and Citizenship in Higher Education: Reclaiming Our Civic Purpose (Flores \& Rogers, 2019). The product of a Kettering Foundation-sponsored collaborative exchange, the edited volume features contributions from U.S. university presidents and community engagement center directors. They and others share diverse perspectives on the complex and courageous roles that executive leaders must play to shape the direction of democracy and civic engagement within and beyond their institutions. As the reviewer points out, the context is one in which higher education institutions are increasingly impacted and shaped by forces of commodification. They are under increased pressure from external and internal forces arising from economic, social, and political factors. Whitford provides a mostly positive assessment of the book, which offers visions and roadmaps for collaborative engagement among community stakeholders, faculty, and students to advance agendas for positive social change.

The second book review, by Anthony Vinciguerra, offers an assessment of the Campus Compact publication titled The Craft of Community Engaged Teaching and Learning: A Guide for Faculty Development (Welch \& Plaxton-Moore, 2019). The reviewer notes that the three-part book, which is written in a conversational style, is a good faculty development resource. According to Vinciguerra, the book provides a virtually encyclopedic introduction to the theory and practice of university-community engagement. Indeed, The Craft of Community Engaged Teaching and Learning provides a theoretically rich yet eminently practical framework for advancing community engagement practice.

\section{Conclusion}

The articles in Volume 8, Issue 1 of IJRSLCE demonstrate that SLCE scholars are taking a variety of approaches to evaluating how stakeholders in campus-community partnerships are putting into practice (or failing to achieve) relationships of mutual respect, shared authority, and knowledge co-creation in ways that advance inclusion, equity, and real reciprocity. As many of the articles summarized herein suggest, the pursuit of such democratic engagement goals will require not an accumulation of new 
surveys but, rather, more sophisticated instruments and innovative methodologies that can both gauge and guide the processes of critical reflection. To be sure, SLCE in higher education continually requires critical reflection on the extent to which partnerships and processes combine effectively to enhance student learning; build community capacity; and transform systems, individuals, organizations, communities, and higher education itself.

\title{
References
}

Flores, W. V., \& Rogers, K. S. (Eds.). (2019). Democracy, civic engagement, and citizenship in higher education: Reclaiming our civic purpose. Rowman \& Littlefield.

Jameson, J. K., Clayton, P. H., \& Jaeger, A. J. (2011). Community-engaged scholarship through mutually transformative partnerships. In L. Harter, J. Hamel-Lambert, \& J. Millesen (Eds.), Participatory partnerships for social action and research (pp. 259-277). Kendall Hunt Publishing.

McBride, A. M., \& Mlyn, E. (Eds.). (2020). Connecting civic engagement and social innovation: Toward higher education's democratic promise. Campus Compact.

Moore, T. L. (2014). Community-university engagement: A process for building democratic communities (Ashe Higher Education Report, Vol. 40, No. 2). Wiley Periodicals.

Public Purpose Institute in Partnership with the Carnegie Foundation. (n.d.). Community engagement classification (U.S.). https://public-purpose.org/initiatives/carnegie-electiveclassifications/community-engagement-classification-u-s/

Saltmarsh, J., Hartley, M., \& Clayton, P. H. (2009). Democratic engagement white paper. New England Resource Center for Higher Education.

Saltmarsh, J., \& Johnson, M. (2020). Campus classification, identity, and change: The elective Carnegie classification for community engagement. Journal of Higher Education Outreach and Engagement, 24(3), 105-114.

Saltmarsh, J., Janke, E. M., \& Clayton, P. H. (2015). Transforming higher education through and for democratic civic engagement: A model for change. Michigan Journal of Community Service Learning, 22(1), 122-127. http://hdl.handle.net/2027/spo.3239521.0022.119

Welch, M., \& Plaxton-Moore, S. (2019). The craft of community-engaged teaching and learning: A guide for faculty development. Campus Compact.

\begin{abstract}
About the Authors
Clayton A. Hurd is director of professional learning and engaged scholarship at Campus Compact and co-editor of the International Journal of Research on Service-Learning and Community Engagement.

Glenn A. Bowen is executive director of the Center for Community Service Initiatives at Barry University and co-editor of the International Journal of Research on Service-Learning and Community Engagement.
\end{abstract}

Correspondence concerning this article should be addressed to Clayton A. Hurd at churd@,compact.org. 